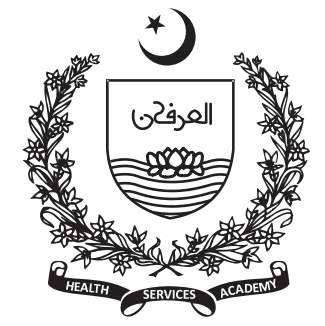

1Department of Mathematics, COMSATS University Islamabad, Sahiwal Campus, Pakistan

2University of Education, Lahore, Multan Campus, Pakistan

Corresponding Author: Rida Ayyaz

Email:

ridaa@cuisahiwal.edu.pk

\section{Exploring the Fundamental Risk Factors of Child Malnutrition: An Application of Proportional Odds Model (POM)}

\author{
Rida Ayyaz ${ }^{1}$, Muhammad Asad Meraj², Fakhar Mustafa ${ }^{1}$
}

\section{Abstract}

Background: This study was designed with the objective to evaluate the fundamental risk factors of malnutrition among children in Lahore city and its outskirts, Pakistan.

Methods: Data of four hundred and five children with age group less than 5 years was collected from Children hospital and Jinnah hospital, Lahore. We used weight-for-height anthropometric index, designed by World Health Organization (WHO), to measure the nutritional status of children. Preliminary analysis was performed by using Pearson Chi-square and Gamma statistics to check the association between factors (demographic, socio-economic and health related variables) and response variable i.e., nutritional status. Then, proportional odds model (POM) was fitted to the information collected.

Results: Of 405 children included in the study, 33\% (135) were found malnourished, whereas, approximately $67 \%$ (270) were found nourished. Findings of the study revealed that child's age, maternal education level, socioeconomic status, maternal age at the birth of child, low birth spacing, status of antenatal-postnatal care, incomplete vaccinations, exclusive breastfeeding, prevalence of fever, cough and recurrent episodes of diarrhea were the significant risk factors of malnutrition. Prevalence of acute respiratory infection (ARI) was turned out to be insignificant risk factor. In this study, parallel lines assumption was satisfied and proportional odds model was fitted well with $p$ value greater than $5 \%$ level of significance.

Conclusion: This paper highlights the significant risk factors that are affecting the child's health. Recognizing and understanding the identified risk factors would be very helpful in prevention of malnutrition in Pakistan.

Keywords: Malnutrition, comparison of children under five years, proportional odds model (POM), anthropometric index, Odds Ratio (OR).

\section{Introduction} Many developing countries have been facing major health problems like 'child malnutrition' for decades. It has been estimated that almost half of the world's malnourished children are residing in South Asian countries. Poor maternal health, recurrent infections, food insecurity, derelict and insufficient health care system and facilities are found to be the most important causes of malnutrition (1). A recent survey report published by the International Food Policy Research Institute highlights 
the severity of the situation where Pakistan has been ranked as a country with alarming hunger level with 22 percent of its population undernourished. Pakistan is placed at 107 in the ranking of 118 developing countries (2). Malnutrition is indeed a key impediment in the development of Pakistan. Well-nourished populations are required for socio-economic growth of the country. Despite of adopting some strategies to address this health issue, no significant change has been observed for the last two decades. Poverty is also considered as one of the major contributors to malnutrition.

Taking into an account the severity of malnutrition, a cross-sectional study was planned considering the data of 135 malnourished and 270 nourished children. Identifying the risk factors of malnutrition among children aged less than five years with application of ordinal regression model was the main objective. The targeted population, were children residing in Lahore city and its outskirts. World Health Organization (WHO) has designed the chart of anthropometric indices for measuring nutritional status of children. Three types of indices such as underweight (low weight-for-age), wasting (low weight-for-height) and stunting (low height-for-age) are used to measure malnutrition level of population aging below five years. In this study, weight-for-height anthropometric index is adopted to check the level of malnutrition in the targeted population. The role of demographic, economic and biological explanatory variables and subsequent development of malnutrition was also evaluated by comparing cases with controls.

Logistic regression models are broadly employed in epidemiological studies to quantify the association between the disease and its risk factors. A study for the analysis of diabetic retinopathy has accentuated the use of ordinal regression models, if response variable is of ordinal nature (3). Recently, Adenomon and John (2020) have modeled the risk factors of hypertension among adults in Nigeria by fitting ordinal regression modeling techniques (4). Many other studies also proposed the importance of ordinal regression models in epidemiology (5-10). Several researchers have also explore the number of risk factors that are associated with malnutrition. A study of Sukkur District explored that parental illiteracy, non-exclusive breastfeeding, low socio-economic status, large family and recurrent episodes of diarrhea as the significant predictors of malnutrition (11). Several other studies valued the low-income group as the most important determinant of malnutrition among children aged $\leq 5$ years (11-16). Another study about malnutrition that was conducted for children of Roma settlements in Serbia, a strong relationship between maternal education and wasting was observed (17). Paternal education was also found to have a significant influence on child's health (11-14, 17). A case-control study was planned in Nepal to explore the determinants of severe acute malnutrition among children (aged less than 5 years) by adopting logistic regression technique (18). Wasihun et al. (2018) planned a cross-sectional study in the Tigray region of Northern Ethiopia and fitted multivariate logistic regression to identify the significant factors of diarrhea and nutritional status (19). According to the Pakistan National Nutritional Survey 2018, four out of every tenth children under the age of five are stunted, and $17.7 \%$ are suffering from wasting. With nearly onethird of children underweight and a high incidence of overweight in the same age range, the burden of malnutrition is becoming increasingly obvious. Thus, malnutrition could be considered as one of the crucial health problems in Pakistan. Socio-economic development of any state requires healthy people with healthy minds. Keeping in view the intensity of the problem, this study was designed with the objective to identify the fundamental risk factors of malnutrition among children aged $\leq 5$ years through statistical modeling.

\section{Methodology}

Data of 405 children were collected through a welldesigned questionnaire from Children hospital and Jinnah hospital, Lahore in the period of three months. Almost twenty-two questions were asked from mothers regarding demographic information, socioeconomic status (monthly income and residence), maternal Body Mass Index (BMI) and child health by conducting face-to-face interview. Weight-for-height, anthropometric index was used to find the nutritional level of the children. One hundred and thirty-five children were malnourished and two hundred and seventy were nourished in the data collected. Only thirteen mothers declined to interview requests. In this study, 'nutritional status was considered the response variable. Weight-for-height anthropometric index was used to assess the nutritional status of children.

Statistical analysis was performed on SPSS version 20. Primarily, the relationship between nutritional status and a set of explanatory variables was determined. 
Pearson chi-square test statistics is used to check the relationship between two nominal variables or if one variable is nominal and other is ordinal. Gamma $(\gamma)$ statistic was proposed by Goodman and Kruskal in 1954. This test statistic is used to check whether there exists significant relationship between two ordinal type variables or not (20). The range of Gamma statistic is $-1 \leq \gamma \leq+1$, representing the negative and positive association, respectively.

The explanatory variables having significant relationship with response variable were further taken up into the multivariate analysis. POM was fitted to the observed dataset. Initially, Walker and Duncan proposed proportional odds model in 1967 and McCullagh made some modifications in the model later (21). The baseline assumption of POM is proportional odds or parallel lines assumption.

Suppose that $Y$ is a response variable having ' $\mathrm{k}$ ' ordered categories $C_{1}, C_{2}, \ldots, C_{k}$, ' $\mathrm{k}$ ' must be greater than two. Let $\left[x_{1}, x_{2}, \ldots, x_{p}\right]$ is the set of 'p' explanatory variables. Now, the effect of ' $p$ ' explanatory variables on different levels of response variable ' $Y$ ' in POM is defined as;

In the logit form;

$$
\begin{aligned}
\operatorname{Pr}(Y & \left.\leq y_{j} / x\right)=\frac{e^{\alpha_{j}-X^{\prime} \beta}}{1+e^{\alpha_{j}-X^{\prime} \beta}}, j \\
& =1,2, \ldots, k
\end{aligned}
$$

$$
\operatorname{logit}\left(\pi_{j}\right)=\log \left(\frac{\pi_{j}}{1-\pi_{j}}\right)
$$

$\alpha_{j}$ are the unknown intercepts (satisfying the condition $\left.\alpha_{1} \leq \alpha_{2} \leq \cdots \leq \alpha_{k}\right), \beta=\left[\beta_{1}, \beta_{2}, \ldots, \beta_{p}\right]^{\prime}$ is a vector of unknown regression coefficients, and $\pi_{j}$ is the cumulative probability. The most recommended statistics for measuring the strength of association is Nagelkerke Psuedo $R^{2}$. Therefore, this measure is used to infer the best fit.

\section{Results}

\section{Preliminary Analysis}

The analysis was performed on the dataset of 135 malnourished and 270 nourished children aged less than five years. The weight-for-height anthropometric index used $\mathrm{z}$-scores as a measure to identify the nutritional status of the children. The nominal explanatory variables in the study were gender (boy or girl), child's age (less than 11 months, 11 - 24 months, 24 - 36 months, 36 - 48 months or greater than 48 months), residential area (urban or rural), number of children in a certain family (less than $3,3-5$ or more than 5), mother's age at the time of child's birth (less than 20 years, 20 - 30 years or more than 30 years), birth spacing (less than 24 months, 24 to 48 months, more than 48 months), breastfeeding status (no breastfeeding, less than 11 weeks, 11 to 19 weeks, 19 to 27 and more than 27 weeks), vaccinations status (no vaccination has been taken, vaccinated partially, completed the course of vaccinations), status of antenatal care (no care, 1 - 9 weeks, 10 - 18 weeks, 19 27 weeks or more than 27 weeks), status of postnatal care (no care, $<2$ weeks, $2-4$ weeks or more than 4 weeks), prevalence of fever and cough (yes or no), prevalence of diarrhea (yes or no) and prevalence of acute respiratory infection (yes or no).

Five ordinal variables, considered in the study, were mother's education (illiterate, under-matriculation, matriculation, intermediate, graduation/higher), father's education (illiterate, under-matriculation, matriculation, intermediate, graduation/higher), monthly household income (less than 10000 rupees, 10000 - 20000 rupees, 20000 - 30000 rupees, 30000 40000 rupees and more than 40000 rupees), mother's BMI (underweight, normal or overweight) and birth weight of child (underweight, normal, overweight).

The findings of checking the association between number of explanatory variables with response variables are given in (Table 1).

Table 1: Explanatory variables and their association with nutritional status

\begin{tabular}{|l|c|c|}
\hline \multicolumn{1}{|c|}{ Variables } & Chi- & P-value \\
\hline Gender & 5.53 & 0.14 \\
\hline Age & 51.68 & $0.00^{*}$ \\
\hline Residential Area & 47.65 & $0.00^{*}$ \\
\hline Number of Children & 13.04 & $0.04^{* *}$ \\
\hline Mother's Age at the Birth & 32.8 & $0.00^{*}$ \\
\hline Birth Spacing (in months) & 49.09 & $0.00^{*}$ \\
\hline Breastfeeding Status (in & 87.32 & $0.00^{*}$ \\
\hline Status of Vaccinations & 73.84 & $0.00^{*}$ \\
\hline Status of Antenatal Care & 66.09 & $0.00^{*}$ \\
\hline Status of Postnatal Care & 68.9 & $0.00^{*}$ \\
\hline Prevalence of Fever and & 49.84 & $0.00^{*}$ \\
\hline Prevalence of Diarrhea & 50.74 & $0.00^{*}$ \\
\hline Prevalence of ARI & 15.23 & $0.00^{*}$ \\
\hline Mother's Education & -0.36 & $0.00^{*}$ \\
\hline Father's Education & -0.41 & $0.00^{*}$ \\
\hline
\end{tabular}




\begin{tabular}{|l|c|c|}
\hline Household Income (Rs.) & -0.28 & $0.00^{*}$ \\
\hline Mother's BMI & -0.18 & $0.03^{* *}$ \\
\hline Child's Birth Weight & -0.11 & 0.28 \\
\hline
\end{tabular}

Fitting the POM

POM is suitable model to identify the significant risk factors in case of ordinal response variable. Parallel lines assumption was checked before fitting POM. The assumption was satisfied with p-value $=0.40$ (Table 2 ). In this study, nutritional status is the response variable. It has four categories: nourished (category 1), mildly malnourished (category 2), moderately malnourished (category 3) and severely malnourished (category 4). This model allows to make a comparison between these categories such as: (i) "category 1" versus "category 2 to 4 " (ii) "category 1 and 2" versus "category 3 and 4 " and (iii) "category 1 to 3 " versus "category 4."

For multivariate analysis, the categories of some variables such as age of children, maternal education and household income were merged into two or three categories. In the first phase of model fitting, POM was fitted to the data set considering child's age, mother's education, income and residential area as explanatory variables (Table 2). Greater risk of malnutrition was observed among children of age less than 24 months $(\mathrm{OR}=2.60,95 \% \mathrm{CI}$ for $\mathrm{OR}=1.28$ 5.28). Mothers having education less than matriculation had increased odds of malnourished children as compared to mothers educated up to matriculation and above $(\mathrm{OR}=2.12,95 \% \mathrm{CI}$ for $\mathrm{OR}=$ 1.25 - 3.57). Household income (OR $=2.01,95 \% \mathrm{CI}$ for $\mathrm{OR}=1.19-3.39)$ and residential area $(\mathrm{OR}=0.33,95 \%$ $\mathrm{CI}$ for $\mathrm{OR}=0.21-0.51$ ) were also found to have a significant effect on child's health. Pearson and Deviance chi-square statistics indicated that model was consistent with the observed data ( $p$-value $=0.13$ and 0.06, respectively). According to Nagelkerke Pseudo $R^{2}$ mentioned in Table 2, almost $23.7 \%$ variation has been explained in response variable due to demographic variables (Table 2).

All the variables, related to maternal and child health were entered into ordinal regression analysis in the second phase. Parallel lines assumption was checked for the second model. Assumption was not violated ( $\mathrm{p}$-value $>5 \%$ level of significance). So, it was concluded that all the explanatory variables had the same effect on different levels of response variable i.e., "nutritional status", only the intercepts were different.
Table 2: Fitting POM considering demographic variables

\begin{tabular}{|c|c|c|c|c|}
\hline Covariates & $\begin{array}{l}\text { Coeffi } \\
\text { cients }\end{array}$ & P-value & $\begin{array}{l}\text { Odds } \\
\text { Ratio }\end{array}$ & $\begin{array}{c}95 \% \text { C.I for } \\
\text { OR }\end{array}$ \\
\hline \multicolumn{5}{|l|}{$\begin{array}{l}\text { Child's Age (in } \\
\text { months) }\end{array}$} \\
\hline$<24$ & 0.96 & $0.008^{*}$ & 2.6 & $1.28-5.28$ \\
\hline $24-48$ & 0.09 & 0.807 & 1.09 & $0.53-2.25$ \\
\hline$>48(\mathrm{r})$ & - & - & 1 & - \\
\hline \multicolumn{5}{|l|}{$\begin{array}{l}\text { Mother's } \\
\text { Education }\end{array}$} \\
\hline $\begin{array}{l}\text { Below } \\
\text { Matriculation }\end{array}$ & 0.75 & $0.005^{*}$ & 2.12 & $1.25-3.57$ \\
\hline $\begin{array}{l}\text { Matriculation } \\
\text { and Above (r) }\end{array}$ & - & - & 1 & - \\
\hline \multicolumn{5}{|l|}{$\begin{array}{l}\text { Household } \\
\text { Income (in Rs.) }\end{array}$} \\
\hline$<20,000$ & 0.7 & $0.009 *$ & 2.01 & $1.19-3.39$ \\
\hline $\begin{array}{l}20,000 \& \\
\text { above }(\mathrm{r})\end{array}$ & - & - & 1 & - \\
\hline \multicolumn{5}{|l|}{ Resident } \\
\hline Urban & & $0.00^{*}$ & 0.33 & $0.21-0.51$ \\
\hline Rural (r) & - & - & 1 & - \\
\hline Intercept 1 & 1.08 & $0.005^{*}$ & & \\
\hline Intercept 2 & 1.8 & $0.00^{*}$ & & \\
\hline Intercept 3 & 2.7 & $0.00 *$ & & \\
\hline $\begin{array}{l}\text { Pearson Chi- } \\
\text { Square }\end{array}$ & 76.73 & 0.13 & & \\
\hline $\begin{array}{l}\text { Deviance Chi- } \\
\text { Square }\end{array}$ & 85.5 & 0.07 & & \\
\hline \multicolumn{5}{|l|}{ Pseudo $R^{2}$} \\
\hline \& Snell Cox & 0.21 & & & \\
\hline Nagelkerke & 0.24 & & & \\
\hline Mcfadden & 0.12 & & & \\
\hline
\end{tabular}

' $r$ ' indicates reference category.

**P-value $<0.05$

Results of statistical analysis revealed that age of mothers between twenty to thirty years at the birth of child had lesser odds $(\mathrm{OR}=0.38,95 \% \mathrm{CI}$ for $\mathrm{OR}=0.21$ - 0.70) of having poorly nourished children as compared to mothers aging more than thirty years. Less than two years of birth interval had three-times 
greater odds of having malnourished children (OR = $3.04,95 \%$ CI for OR $=1.23-7.40)$. This study illustrated breastfeeding as the most important determinant of child's health. The higher risk of being malnourished was observed among children with reduced breastfeeding as compared to the children who were breastfed for more than six months $(\mathrm{OR}=$ $5.50,95 \% \mathrm{CI}$ for OR $=2.44-12.38$ ). The nourishment of infants was also influenced by the vaccinations. Children who had not completed the course of vaccinations were found with greater risk of malnutrition $(\mathrm{OR}=2.83,95 \% \mathrm{CI}$ for $\mathrm{OR}=1.60-5.00)$. Another explanatory variable, maternal status of antenatal $(\mathrm{OR}=3.02,95 \% \mathrm{CI}$ for $\mathrm{OR}=1.12-8.15)$ and postnatal care $(\mathrm{OR}=3.98,95 \% \mathrm{CI}$ for $\mathrm{OR}=1.31$ 12.10) had significant influence on child's health. Children who had not suffered from fever and cough were at smaller risk of developing malnutrition (OR = $0.72,95 \% \mathrm{CI}$ for $\mathrm{OR}=0.43-1.22)$, when compared with those who had suffered from fever and cough in the last two months before data collection. Similarly, lesser odds of malnutrition were observed among children who had not experienced recurrent episodes of diarrhea $(\mathrm{OR}=0.40,95 \% \mathrm{CI}$ for $\mathrm{OR}=0.24-0.68)$. The prevalence of ARI turned out to be insignificant predictor of malnutrition in model fitting $(p$-value $=$ $0.62)$.

Table 3: Fitting POM considering health-related variables

\begin{tabular}{|l|c|c|c|c|}
\hline \multicolumn{1}{|c|}{ Covariates } & $\begin{array}{c}\text { Coeffici } \\
\text { ents }\end{array}$ & $\begin{array}{c}\text { P- } \\
\text { value }\end{array}$ & OR & $\begin{array}{c}95 \% \text { C.I for } \\
\text { OR }\end{array}$ \\
\hline $\begin{array}{l}\text { Mother's Age at } \\
\text { the Birth of Child }\end{array}$ & \multicolumn{5}{|l|}{} \\
\hline$<20$ & -0.34 & 0.4 & 0.71 & $0.32-1.57$ \\
\hline $20-30$ & -0.97 & $0.00^{*}$ & 0.38 & $0.21-0.70$ \\
\hline$>30$ (r) & - & - & 1 & - \\
\hline $\begin{array}{l}\text { Birth Spacing (in } \\
\text { months) }\end{array}$ & \multicolumn{5}{|l|}{} \\
\hline$<24$ & 1.11 & $0.00^{*}$ & 3.04 & $1.23-7.40$ \\
\hline $24-48$ & 1.03 & $0.02^{* *}$ & 2.8 & $1.20-6.52$ \\
\hline$>48$ (r) & - & - & 1 & - \\
\hline $\begin{array}{l}\text { Breastfeeding } \\
\text { Status }\end{array}$ & & \multicolumn{5}{|l|}{} \\
\hline No breastfeeding & 1.71 & $0.00^{*}$ & 5.5 & $2.44-12.38$ \\
\hline$<11$ & 0.43 & 0.09 & 1.53 & $0.69-3.40$ \\
\hline $11-19$ & 0.18 & 0.3 & 1.19 & $0.46-3.06$ \\
\hline $19-27$ & -0.17 & 0.4 & 0.84 & $0.35-2.01$ \\
\hline$>27$ (r) & - & - & 1 & - \\
\hline $\begin{array}{l}\text { Vaccinations } \\
\text { Received }\end{array}$ & 1.04 & $0.00^{*}$ & 2.83 & $1.60-5.00$ \\
\hline No &
\end{tabular}

\begin{tabular}{|c|c|c|c|c|}
\hline Yes (r) & - & - & 1 & - \\
\hline \multicolumn{5}{|l|}{$\begin{array}{l}\text { Status of Antenatal } \\
\text { Care (in weeks) }\end{array}$} \\
\hline No care & 1.1 & $0.03^{* *}$ & 3.02 & $1.12-8.15$ \\
\hline $1-9$ & 1.52 & $0.00^{*}$ & 4.55 & $1.68-12.29$ \\
\hline $10-18$ & 0.64 & $0.01^{* *}$ & 1.89 & $0.73-4.93$ \\
\hline $19-27$ & 1.35 & $0.00^{*}$ & 3.84 & $1.59-9.29$ \\
\hline $28-36(\mathrm{r})$ & - & - & 1 & - \\
\hline \multicolumn{5}{|l|}{$\begin{array}{l}\text { Status of Postnatal } \\
\text { Care (in weeks) }\end{array}$} \\
\hline No care & 1.38 & $0.00^{*}$ & 3.98 & $1.31-12.10$ \\
\hline$<2$ & 1.01 & $0.04^{* *}$ & 2.75 & $1.04-7.29$ \\
\hline $2-4$ & 0.93 & 0.045 & 2.53 & $1.02-6.27$ \\
\hline$>4(\mathrm{r})$ & - & - & 1 & - \\
\hline \multicolumn{5}{|l|}{$\begin{array}{l}\text { Prevalence of } \\
\text { Fever and Cough }\end{array}$} \\
\hline No & -0.33 & $\underset{* *}{0.048}$ & 0.72 & $0.43-1.22$ \\
\hline Yes (r) & - & - & 1 & - \\
\hline $\begin{array}{ll}\begin{array}{l}\text { Prevalence of } \\
\text { Diarrhea }\end{array} & \\
\text { No }\end{array}$ & -0.92 & $0.00^{*}$ & 0.4 & $0.24-0.68$ \\
\hline Yes (r) & - & - & 1 & - \\
\hline $\begin{array}{l}\text { Prevalence of ARI } \\
\text { No }\end{array}$ & -0.49 & 0.12 & 0.62 & $0.34-1.13$ \\
\hline Yes (r) & - & - & 1 & - \\
\hline Intercept 1 & 1.66 & $0.02^{\star *}$ & & \\
\hline Intercept 2 & 2.94 & $0.00^{*}$ & & \\
\hline Intercept 3 & 4.44 & $0.00^{*}$ & & \\
\hline $\begin{array}{l}\text { Pearson Chi- } \\
\text { Square }\end{array}$ & 803.89 & 1 & & \\
\hline $\begin{array}{l}\text { Deviance Chi- } \\
\text { Square }\end{array}$ & 504.4 & 1 & & \\
\hline \multicolumn{5}{|l|}{ Pseudo $R^{2}$} \\
\hline Cox \& Snell & 0.51 & & & \\
\hline Nagelkerke & 0.59 & & & \\
\hline Mcfadden & 0.36 & & & \\
\hline
\end{tabular}

Intercepts given in Table 3 satisfy the assumption of proportional odds model i.e., intercept $1<$ intercept 2 $<$ intercept 3 . The models were fitted well according to Pearson and Deviance chi-square test statistics (pvalue $=1.00)$. Nagelkerke $R^{2}$ revealed that approximately $59 \%$ variation in response variable can be explained with the explanatory variables that are related to maternal and child health (Table 3).

\section{Discussion}

Malnutrition is a multifarious and widespread health issue especially in developing countries including Pakistan. Reduction in the rate of malnutrition is 
required for sustainable development of any country. Our study has identified major risk factors of this disease by applying POM. Gender bias is not found $(p$-value $=0.14)$ in contrast to the study conducted in Cambodia (22). Parental education levels and household income are the significant predictors of nourishment among children; these findings are supported by several other studies (11-14, 23-24). Similar to our findings, Das and Hossain reported maternal BMI as the significant predictor of malnutrition (14). Another study of Paul et al. explored maternal BMI and education as the significant risk factors of malnutrition in children $\leq 5$ years of age through POM in Bangladesh (25). The results are similar to our study. Lack of breastfeeding, short birth interval and whether the child has completed the course of vaccinations or not are found to be highly significant risk factors ( $\mathrm{p}$-value $=0.00$ ), also reported in the previous studies $(11,23)$. A study conducted by Taneja et al. has reported that poor health of mother during pregnancy adversely affects the child growth in India (26). Prevalence of ARI has not shown significant influence on child's health as compared to prevalence of fever, cough and recurrent episodes of diarrhea. Whereas, a study conducted in Bangladesh predicted higher prevalence of malnutrition among children who suffered from ARI (14). Another variable, 'birth weight of children' was found to be an insignificant risk factor of malnutrition ( $p$-value $=0.28)$. However, in contrast to our study, it was observed to be an important determinant of nutritional status in a study conducted by Delpeuch et al. (2000) in Africa (15).

Results of POM regarding status of antenatal care were statistically significant $(p$-value $=0.03)$. The findings of study have shown three times greater odds of having malnourished children of mothers who do not take antenatal-postnatal care $(\mathrm{OR}=3.02$ and 3.98), respectively (Table 3). Many studies in epidemiology have proposed the use of ordinal regression models, when response variable has ordered categories $(5,8$ 10).

\section{Conclusion}

In Pakistan, about half of all children are chronically malnourished, while $11 \%$ are critically malnourished. These circumstances add to high rates of death and sickness among children under the age of five years, hindering their mental and physical development and also leaving huge impact on economic growth. This study identified significant risk factors that contribute in malnutrition of children under five years age in Lahore, Pakistan. It is concluded that child's age, maternal education level, socio-economic status, maternal age, low birth spacing, status of antenatalpostnatal care, incomplete vaccinations, non-exclusive breastfeeding, recurrent episodes of diarrhea, prevalence of fever and cough are statistically significant risk factors associated with malnutrition. Prevalence of ARI is found to be an insignificant risk factor of malnutrition among children. POM has provided good results, because the assumption is satisfied and model provides the best fit on the data set with p-value greater than $5 \%$ level of significance. As, the nutritional status is a variable of ordinal nature, therefore, we have adopted the technique of ordinal regression instead of multivariate logistic regression as compared to other studies performed earlier. In this paper, weight-for-height (wasting) anthropometric index was used to assess the nutritional status of children. In future, nutritional status would be measured by using weight-for-age and height-for-age anthropometric index to check the prevalence of underweight and stunting in Pakistan. Birth weight of children should be recorded carefully. Poor sanitary conditions and use of dung or wood for cooking within the household premises, a very common practice in rural Pakistan, could be explored as the potential risk factors for malnutrition in further studies.

\section{Acknowledgment}

We are thankful to all the parents and children participated in this study. We are greatly thankful to the staff of Children hospital and Jinnah hospital, Lahore especially Dr. Mubashir Salim for his help in collecting data. We also thanks Miss Ciara Farren (The University of Edinburgh) for English style Editing.

\section{Conflict of Interest}

All contributing authors declare no conflict of interest.

\section{Funding}

No external source of funding.

\section{References:}

1. Linnemayr S, Alderman H, Ka A. Determinant of malnutrition in Senegal: Individual, household, community variables, and their interaction. Economics and Human Biology. 2008; 6(2): 252-26.

2. Dawn.com (2020) Pakistan has serious hunger level: survey. Available at: 
http:/ /www.dawn.com/news/1289693/pakistan-hasserious-hunger-level-survey

3. Kulothungan V, Subbiah M, Ramakrishnan R, et al. Identifying associated risk factors for severity of diabetic retinopathy from ordinal logistic regression models. Biostatistics and Epidemiology. 2018; 2(1): 3446.

4. Adenomon MO, John DO. Modelling Hypertension and Risk Factors among Adults Using Ordinal Logistics Regression Model. Preprints 2020, 202001.0291 (doi: 10.20944/preprints. v1).

5. Abreu MNS, Siqueira AL, Cardoso CS, et al. Ordinal logistic regression models: Application in quality of life studies. Cadernos de Saúde Pública. 2008; 24: s581-s591.

6. Adeleke KA, Adepoju AA. Ordinal logistic regression model: An application to pregnancy outcomes. Journal of Mathematics and Statistics. 2010; 6(3): 279-285.

7. Afroja S, Kabir MR, Islam MA. Analysis of determinants of severity levels of childhood anemia in Bangladesh using a proportional odds model. Clinical Epidemiology and Global Health. 2019.

8. Ananth, CV, Kleinbaum, DG. Regression models for ordinal responses: a review of methods and applications. International journal of epidemiology. 1997; 26(6), 1323-1333.

9. Bender R., Grouven, U. Ordinal logistic regression in medical research. Journal of the Royal College of Physicians of London. 1997; 31(5), 546-551.

10. Holtbrugge W, Schumacher $M$. A comparison of regression models for the analysis of ordered categorical data. Applied Statistics. 1991; 249-259.

11. Jamro B, Junejo AA, Lal S, et al. Risk factors for severe acute malnutrition in children under the age of five year in Sukkur. Pakistan Journal of Medical Research. 2012; 51(4): 111.

12. Khalid N, Aslam Z, Kausar F, et al. Maternal malnutrition and its kick on child growth: An alarming trim for Pakistan. Journal of Food, Nutrition and Population Health. 2017; 1(3): 24.

13. Anderson AK, Bignell W, Winful S, et al. Risk factors for malnutrition among children 5-years and younger in the akuapim-north district in the Eastern Region of Ghana. Current research Journal of Biological sciences. 2010; 2(3), 183-188.

14. Das S, Hossain MZ, Islam MA. Predictors of child chronic malnutrition in Bangladesh. Proceedings of the Pakistan Academy of Sciences. 2008; 45(3), 137-155.

15. Delpeuch F, Traissac P, Martin-Prével Y, et al. Economic crisis and malnutrition: socioeconomic determinants of anthropometric status of preschool children and their mothers in an African urban area. Public Health Nutrition. 2000; 3(01), 39-47.
16. Van de Poel E, Hosseinpoor AR, Speybroeck N, et al. Socioeconomic inequality in malnutrition in developing countries. Bulletin of the World Health Organization. 2008; 86(4): 282-291.

17. Janevic T, Petrovic O, Bjelic I, et al. Risk factors for childhood malnutrition in Roma settlements in Serbia. BMC Public Health. 2010; 10(1), 1.

18. Pravana NK, Piryani S, Chaurasiya SP, Kawan R, Thapa RK, Shrestha S. Determinants of severe acute malnutrition among children under 5 years of age in Nepal: a community-based case-control study. BMJ open. 2017 Aug 1;7(8).

19. Wasihun AG, Dejene TA, Teferi M, Marugán J, Negash L, Yemane D, McGuigan KG. Risk factors for diarrhoea and malnutrition among children under the age of 5 years in the Tigray Region of Northern Ethiopia. PLoS One. 2018 Nov 26;13(11):e0207743.

20. Agresti A. Categorical Data Analysis. 2nd edition. New York: John Wiley \& Sons, 2003.

21. McCullagh P. Regression models for ordinal data. Journal of the Royal Statistical Society: Series B (Methodological). 1980; 42(2): 109-127.

22. Wieringa FT, Gauthier L, Greffeuille V, et al. Identification of acute malnutrition in children in Cambodia requires both mid upper arm circumference and weight-for-height to offset gender bias of each indicator. Nutrients. 2018; 10(6): 786.

23. Endris N, Asefa H, Dube L. Prevalence of malnutrition and associated factors among children in rural Ethiopia. BioMed Research International. 2017.

24. Rahman MS, Howlader T, Masud MS, et al. Association of low-birth weight with malnutrition in children under five years in Bangladesh: Do mother's education, socioeconomic status, and birth interval matter? PloS ONE. 2016; 11(6): e0157814.

25. Paul GK, Nesa MK, Mondal SK. Application of proportional odds model in identifying contributing factor of under-five child malnutrition in Bangladesh: A case study in Tangail district. Journal of Health Research and Reviews. 2018; 5(3): 128.

26. Taneja S, Chowdhury R, Dhabhai N, et al. Impact of an integrated nutrition, health, water sanitation and hygiene, psychosocial care and support intervention package delivered during the pre-and peri-conception period and/or during pregnancy and early childhood on linear growth of infants in the first two years of life, birth outcomes and nutritional status of mothers: study protocol of a factorial, individually randomized controlled trial in sIndia. Trials. 2020; 21(1): 127. 